Celal Bayar University Journal of Science

\title{
Evaluation of the Bearing Capacity of Shallow Strip Foundations Resting on Sandy Soils with Analytical and Numerical Methods
}

\author{
Emrah Dağl1 ${ }^{1}$ (D), Ömer Faruk Çapar²*iD \\ ${ }^{1}$ Zonguldak Bülent Ecevit Üniversitesi, Zonguldak, Turkey \\ ${ }^{2}$ Adana Alparslan Türkeș Bilim ve Teknoloji Üniversitesi, Adana, Turkey \\ *ofcapar@atu.edu.tr \\ *Orcid:0000-0002-6325-8233
}

Received: 18 March 2020

Accepted: 29 December 2020

DOI: $10.18466 /$ cbayarfbe. 705653

\begin{abstract}
In the present study, the bearing capacities of coarse graded soils beneath shallow strip foundations at the surface $\left(\mathrm{D}_{\mathrm{f}}=0\right)$ were calculated by means of analytical and numerical methods. First, all necessary geotechnical properties of the soil were achieved at seven different relative density values of the soil in terms of correlations between friction angle $(\phi)$ and dry density $\left(\gamma_{d}\right)$. Second, 56 bearing capacity analyses of shallow strip foundation systems at surface were conducted by changing the soil parameters and the width of the foundations with analytical and finite element methods (FEM). The Mohr-Coulomb, elasticplastic, model was chosen for this research. Although explicit analytic solutions were obtained without any difficulty, FEM provided only the load-deformation response at the base of the footing from the models. Because of that, some prediction methods were used to evaluate and find the bearing capacity of the soils beneath the foundation from the load-deformation responses. The results of analytic and numerical analyses of the shallow strip foundation laying on loose soil models gave very similar values. Although, very similar bearing capacity values of the foundations laying on dense soil models were calculated using analytical methods, the results of numerical methods were very divergent and scattered at the same conditions. The reason for this is due to some limitations of the elastic-plastic model and prediction methods.
\end{abstract}

Keywords: Bearing Capacity, Finite Element, Sandy Soils, Shallow Foundation

\section{Introduction}

Shallow foundations are usually requested due to their ability to transmit the loads of the structures to be designed. For this purpose, the bearing capacity of the foundation soil needs to be determined. To find the bearing capacity of the soil beneath a shallow foundation system, real-size test systems are required. In addition, it is necessary to continue the loading to exceed the bearing capacity of the foundation soil. This process is a formidable task and very expensive. Because of those difficulties, Limit equilibrium methods used widely in applications are the general bearing capacity equations created by Terzaghi [1] Meyerhof [2], Vesic [3] and Eurocode 7 [4,5], etc. All of these analytical methods give comparable values of the bearing capacity of the foundation soils based on both the width of the footing (B), the embedment depth of the footing $\left(D_{f}\right)$, cohesion $\left(c_{u}\right)$, internal friction angle $(\phi)$, and unit weight $(\gamma)$ of the soil. The parameters of the foundation soil are found by in-situ and laboratory tests.

Currently, with the development of computer and simulation technologies, numerical methods and applications of engineering designs are increasing progressively. With the help of data obtained from experimental studies conducted in the field and laboratory in geotechnical engineering, the use of numerical methods has become a necessity in designs that require a lot of load calculations. Therefore, the options given to the users according to the number of computer software offered to be used in the solution of basic and soil mechanics problems and the scope of the problems are increasing gradually.

Numerical models are convergent approaches, although they attempt to represent actual ground behavior. Many factors, such as analysis accuracy, number of nodes of selected finite elements and limits of solution functions, 
affect the results. Therefore, the results obtained must be interpreted correctly [6-10].

The finite element method (FEM) has been widely used for the simulation of geotechnical problems all around the world. The bearing capacity of footings on graded soils has been researched so far with software using FEM by several authors [6-14].

In this study, the bearing capacity analysis of strip foundations at surface $\left(\mathrm{D}_{\mathrm{f}}=0\right)$ on sandy soils was carried out both analytically and numerically. The loaddeformation relationship of the numerical modeling is examined by the finite element method. The loaddisplacement curves in the literature have been reexamined with numerical estimation methods and the bearing capacity has tried to be predicted, and the similarities and differences have been discussed by comparing the bearing capacity values obtained via numerical and analytical methods.

\section{Analytical Methods}

The first study related with the bearing capacity of shallow foundations was performed by Terzaghi [1] associated with Prandtl's theory. The foundation was homogeneous and isotropic and only has internal friction angle $(\phi)$ and cohesion (c). It was assumed that there is no volumetric change during the deformation. Following this approach, many theories and solutions have been developed for bearing capacity calculations under different soil, foundation and load conditions. Terzaghi [1], Meyerhof [2] and Vesic [3] were the most commonly used theories. However, the shallow foundation approach called Eurocode 7 has been used in European Union countries and Turkey since 2010 [4,5].

\subsection{Terzaghi Bearing Capacity Theory}

Terzaghi [1] developed a theory related with the bearing capacity of rigid, strip and shallow foundations resting on homogeneous soils. There is no shape, depth, compression, inclined load, inclined soil and inclined foundation factors in the bearing capacity equation. Terzaghi [1] suggests the following equation for the strip foundations as the following:

$$
q_{u}=c N_{c}+q N_{q}+0.5 \gamma B N_{\gamma}
$$

where $\mathrm{N}_{\mathrm{c}}, \mathrm{N}_{\mathrm{q}}$ and $\mathrm{N}_{\gamma}$ are the bearing capacity factors, $\mathrm{q}$ is the surcharge load per unit area $\left(\gamma D_{f}\right) . \gamma$ and $D_{f}$ are the unit weight of the foundation soil and the depth of the footing, respectively. B is the width of the footing. In this study, since strip foundations are located on the surface, $\mathrm{q}$ becomes zero and the second term of the equation 2.1 is eliminated. Terzaghi's [1] bearing capacity factors are calculated according to formulas given in Table 1.
In Table $1, K_{p \gamma}$ is a coefficient depending on the internal friction angle $(\phi)$ and Terzaghi $[1,15]$ gave the values of $\mathrm{K}_{\mathrm{p} \gamma}$ only for certain $\phi$ angles. In this study, the values were generated by using the following curve fitting equation. $\phi$ must be used in degree in the equation [10] as follows:

$$
K_{p \gamma}=8.4868+2.3427 e^{0.0971 \phi}+0.0000208 e^{0.343 \phi}
$$

\subsection{Meyerhof Bearing Capacity Theory}

Meyerhof [2] included the part of shearing surface remaining on the foundation base for the calculation of the bearing capacity unlike Terzaghi's [1] theory. In Terzaghi's [1] bearing capacity method, the angle of the wedge with the horizontal axis is $\phi$ while it is equal to $45+\phi / 2$. The foundation base is very frictional in Meyerhof's bearing capacity method like Terzaghi's [1]. Meyerhof [2], obtained equation 2.3 by developing Terzaghi's [1] equations with shape $\left(\mathrm{F}_{\mathrm{cs}}, \mathrm{F}_{\gamma \mathrm{s}}\right)$, depth $\left(\mathrm{F}_{\mathrm{cd}}\right.$, $\left.F_{\gamma d}\right)$ and inclined load $\left(F_{c i}, F_{\gamma i}\right)$ factors. In this study, the second term of the equations of 2.3, 2.4 and 2.5 were removed since there is no depth for this study meaning $\mathrm{qN}_{\mathrm{q}}=0$ as follows:

$$
q_{u}=c N_{c} F_{c S} F_{c d} F_{c i}+0.5 \gamma B N_{\gamma} F_{\gamma s} F_{\gamma d} F_{\gamma i}
$$

Table 1. Equations of the bearing capacity factors for some researchers $[1,2,3,4,5,10]$

\begin{tabular}{cccc}
\hline Researcher & $\mathrm{N}_{\mathrm{c}}$ & $\mathrm{N}_{\mathrm{q}}$ & $\mathrm{N}_{\gamma}$ \\
\hline Terzaghi & $\cot \varphi\left(N_{q}-1\right)$ & $\frac{e^{2\left(\frac{3 \pi}{4}-\frac{\varphi}{2}\right) \tan \varphi}}{2 \cos ^{2}\left(45+\frac{\varphi}{2}\right)}$ & $\frac{1}{2}\left(\frac{K_{p \gamma}}{\cos ^{2} \varphi}-1\right) \tan \varphi$ \\
Meyerhof & $\cot \varphi\left(N_{q}-1\right)$ & $\tan ^{2}\left(45+\frac{\varphi}{2}\right) e^{\pi \tan \varphi}$ & $\left(N_{q}-1\right) \tan 1.4 \varphi$ \\
Vesic & $\cot \varphi\left(N_{q}-1\right)$ & $\tan ^{2}\left(45+\frac{\varphi}{2}\right) e^{\pi \tan \varphi}$ & $2\left(N_{q}+1\right) \tan \varphi$ \\
Eurocode & $\cot \varphi\left(N_{q}-1\right)$ & $\tan ^{2}\left(45+\frac{\varphi}{2}\right) e^{\pi \tan \varphi}$ & $2\left(N_{q}-1\right) \tan \varphi$ \\
\hline
\end{tabular}

\subsection{Vesic Bearing Capacity Theory}

Vesic [3] proposed a theory related with the bearing capacity of shallow foundations. This theory is almost the same with the hypothesis accepted in Meyerhof's [2] bearing capacity theory, just the bearing capacity factor called $\mathrm{N}_{\gamma}$ has a different approach. Vesic developed Meyerhof's [2] bearing capacity equation by adding the inclined soil $\left(\mathrm{F}_{\mathrm{cg}}, \mathrm{F}_{\gamma \mathrm{g}}\right)$, inclined base $\left(\mathrm{F}_{\mathrm{cb}}, \mathrm{F}_{\gamma \mathrm{b}}\right)$ and compressibility $\left(\mathrm{F}_{\mathrm{cc}}, \mathrm{F}_{\gamma \mathrm{c}}\right)$ factors. Vesic's extended bearing capacity equation (2.4) is given below as:

$$
\begin{aligned}
q_{u}=c N_{c} F_{c s} F_{c d} F_{c i} F_{c c} & F_{c g} F_{c b} \\
& +0.5 \gamma B N_{\gamma} F_{\gamma s} F_{\gamma d} F_{\gamma i} F_{\gamma c} F_{\gamma g} F_{\gamma b}(\mathbf{2 . 4})
\end{aligned}
$$

In the equations of $2.3,2.4$ and 2.5 , factors of shape, depth, inclined load, compressibility, inclined soil and inclined base were calculated as 1.0 in terms of foundation and load types along with soil parameters. In Eurocode, no depth factors are given. They may be 
chosen by European countries and added in their Annex of Eurocode.

\subsection{Eurocode Bearing Capacity Theory}

The Eurocode [4,5] bearing capacity method has been used compulsorily among the member states of the European Union since 2010. Assumptions of the Eurocode [4] bearing capacity theory are the same as Meyerhof's [2] and Vesic's bearing capacity method. The Eurocode [4] bearing capacity equation does not have inclined soil, depth and compression factors unlike Vesic's [3] bearing capacity equation. Equation 2.5 is used to calculate the Eurocode [4] bearing capacity as shown below:

$$
q_{u}=c N_{c} F_{c s} F_{c i} F_{c b}+0.5 \gamma B N_{\gamma} F_{\gamma s} F_{\gamma i} F_{\gamma b}
$$

In the equations of 2.3, 2.4 and 2.5, factors of shape, depth, inclined load, compressibility, inclined soil and inclined base were calculated as 1.0 in terms of foundation and load types along with soil parameters. In Eurocode, no depth factors are given. They may be chosen by European countries and added in their Annex of Eurocode.

\section{Analytical Methods}

Geostudio 2012 [16] software utilizing the finite element method was used in order to evaluate the bearing capacity of a shallow foundation resting on soil. Displacement boundary conditions were specified between $0.0025 \mathrm{~m} / \mathrm{sec}$ and $0.005 \mathrm{~mm} / \mathrm{sec}$ under the along with footings in order to pushing into the soil and then equivalent vertical forces were computed. As a result of analysis, load-deformation graphs were derived.

The bearing capacity and deformation were calculated separately in analytic bearing capacity calculations. Thus, it is not possible to obtain a load-deformation graph. This graph can be created only in full-scale insitu and laboratory tests. Experimental work is not only expensive but also difficult to apply on site conditions having huge foundation dimensions. Thankfully, numerical methods like the finite element method, it becomes easy to get load-deformation graphs [17]. However, ultimate bearing load/pressure is not achieved easily in both experimental works and numerical modelling. Therefore, some prediction methods shortly explained below were developed in order to get the ultimate load [18,19,20,21,22].

\subsection{Brinch Hansen Method}

According to the Brinch Hansen [18] method, in the load-displacement curve plotted experimentally or numerically, a stress value is first estimated from the plastic region $\left(\mathrm{q}_{1}=\mathrm{q}_{\mathrm{cap}}\right)$ and the corresponding displacement value $\left(s_{1}\right)$ is determined. Then the $\mathrm{s} 1$ value is taken half $\left(\mathrm{s}_{2}=0.5 \mathrm{~s}_{1}\right)$ and the corresponding stress value $\left(\mathrm{q}_{2}\right)$ is determined. If $\mathrm{q}_{2}$ is $90 \%$ of the initial stress value $\left(\mathrm{q}_{1}=\mathrm{q}_{\text {cap }}\right)$, $\mathrm{q}_{\text {cap }}$ gives the bearing strength of the relevant foundation. This situation shows that the assumed $\mathrm{q}_{\text {cap }}$ value is an iteration process that should continue until it meets these conditions [7].

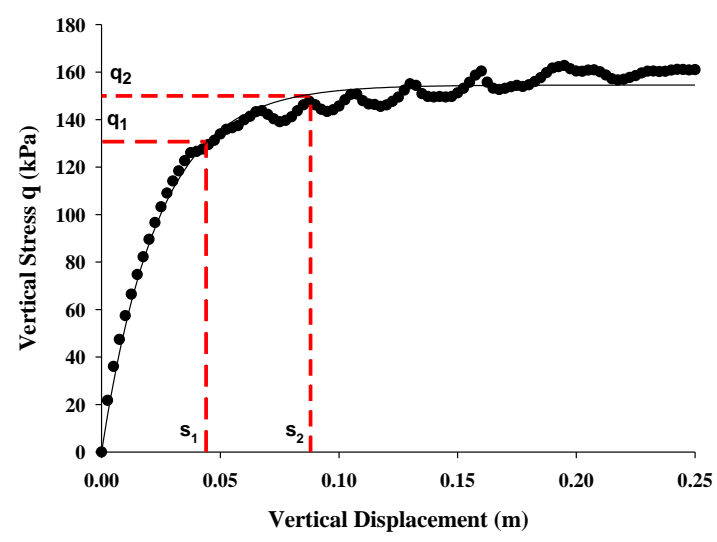

Figure 1. Presentation of Brinch Hansen's method for $\phi=28^{\circ}$ and $\mathrm{B}=1 \mathrm{~m}[10]$.

In Figure 1, there is a sample of Brinch Hansen's [8] method having $1 \mathrm{~m}$ of foundation width (B) and an internal friction of $28^{\circ}$. Deformation-load curve obtained from Geostudio [16] software of Sigma/W module were transformed to a deformation-stress curve. Then the best-fit curve was obtained from the data of deformation and stress values. In the solver application of MS Excel program, the value that makes $\mathrm{q}_{2} / \mathrm{q}_{1}=0.9$ were found while $\mathrm{s}_{2}=0.088 \mathrm{~m}$. According to this method, ultimate bearing pressure was found to be $148.71 \mathrm{kPa}$.

\subsection{De Beer Method}

In the De Beer [19] method, stress increases are calculated by dividing the load values into the foundation area. The load-displacement(s) graph is plotted on a logarithmic scale as seen in Figure 2. According to the De Beer [19] method, the tangent of the first linear portion of the elastic region and the tangent of the second linear portion of the plastic region are drawn. Two lines are extended till they intersect each other. The point of intersection read on the y-axis is found to be the ultimate bearing pressure of the soil model under the strip foundation.

In Figure 2, a sample of De Beer's [19] method having a foundation width of $1 \mathrm{~m}$ and an internal friction angle of $28^{\circ}$ applied on this study was shown. The linear portion of the first region and the second region were determined. Then the trend line of each linear regions was extended until they intersected. The y-axis value of the point of intersection indicated that the ultimate bearing capacity of this example is $139.83 \mathrm{kPa}$. 


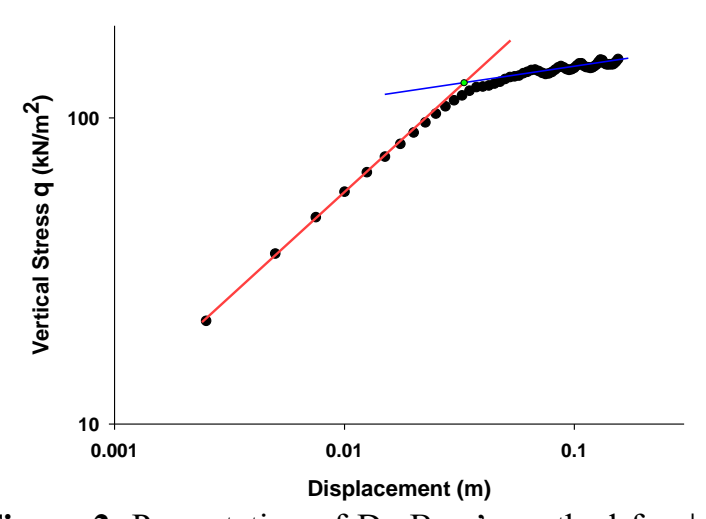

Figure 2. Presentation of De Beer's method for $\phi=28^{\circ}$ and $\mathrm{B}=1 \mathrm{~m} \mathrm{[10]}$.

\subsection{Chin Transformed Axes Method}

According to Chin [20] transformed axes method, the bearing capacity is calculated by the relationship between pseudo deformation $\left(\varepsilon_{\mathrm{s}}=\mathrm{s} / \mathrm{B}\right)$ and the ratio of pseudo deformation and stress $\left(\varepsilon_{\mathrm{s}} / \mathrm{q}\right)$ as:

$$
q=\frac{\varepsilon_{S}}{\frac{1}{k_{i}}+\frac{\varepsilon_{S}}{q_{u l t}}}
$$

or

$$
\frac{\varepsilon_{s}}{q}=\frac{1}{q_{u l t}}+\frac{1}{k_{i}}
$$

where $\mathrm{q}_{\text {ult }}=$ ultimate bearing pressure, $\mathrm{k}_{\mathrm{i}}=$ initial stiffness when $\mathrm{s}=0$.

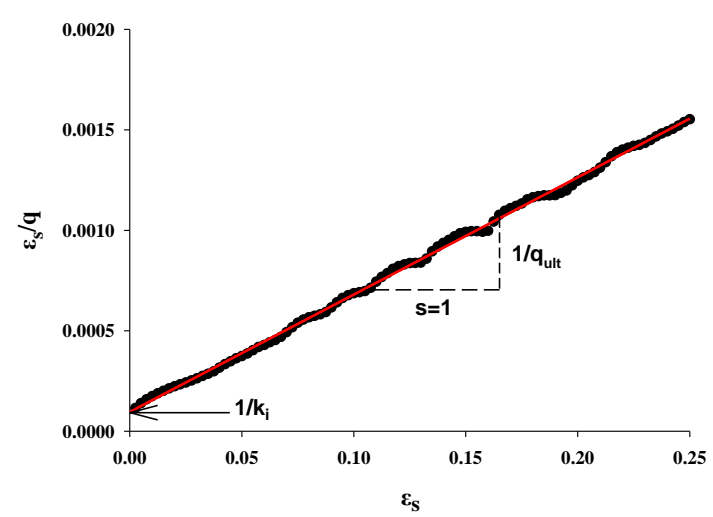

Figure 3. Presentation of the Chin Transformed Axes method for $\phi=28^{\circ}$ and $\mathrm{B}=1 \mathrm{~m} \mathrm{[10]}$.

One of the samples $\left(\mathrm{B}=1 \mathrm{~m}\right.$ and $\left.\phi=28^{\circ}\right)$ for Chin's [20] transformed axes method is seen in Figure 3. Pseudo deformation is equal to $\mathrm{s} / \mathrm{B}$ which means that $\varepsilon_{\mathrm{s}}=\mathrm{s}$ while $\mathrm{B}=1 \mathrm{~m}$. Therefore, the values for the $\mathrm{x}$-axis of the graph is similar with other methods (De Beer [19], $\mathrm{s} / \mathrm{B}=10 \%$ [21] and Brinch Hansen [18]). In the graph of Figure 3, a y-axis was created by dividing pseudo deformation into stress. The linear regression curve is applied on the obtained curve. The inverse of the slope of the linearly obtained equation gives the bearing capacity value. In this example, bearing capacity was found to be 171.26 $\mathrm{kPa}$.

\section{4. s/B Method}

According to this criterion, the bearing capacity of vertically loaded foundations is defined as the stress at the time when the vertical displacement occurring on the soil is equal to $10 \%$ of the foundation width [21]. According to the method used, the load-displacement curve obtained from numerical analysis is transformed into the stress-displacement curve according to its foundation area. The bearing capacity is the stress value corresponds to $10 \%$ of the foundation width.

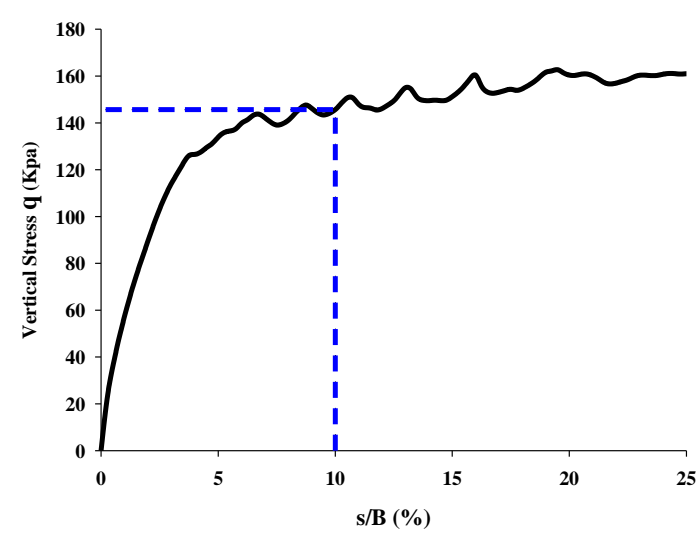

Figure 4. Presentation of $\mathrm{s} / \mathrm{B}$ method for $\phi=28^{\circ}$ and $\mathrm{B}=1 \mathrm{~m}$.

In this example, the $\mathrm{s} / \mathrm{B}=10$ method was applied for $\mathrm{B}=1 \mathrm{~m}$ and $\phi=28^{\circ}$. According to calculations with this method as seen in Figure 4, the bearing capacity value was found to be $145.70 \mathrm{kPa}$.

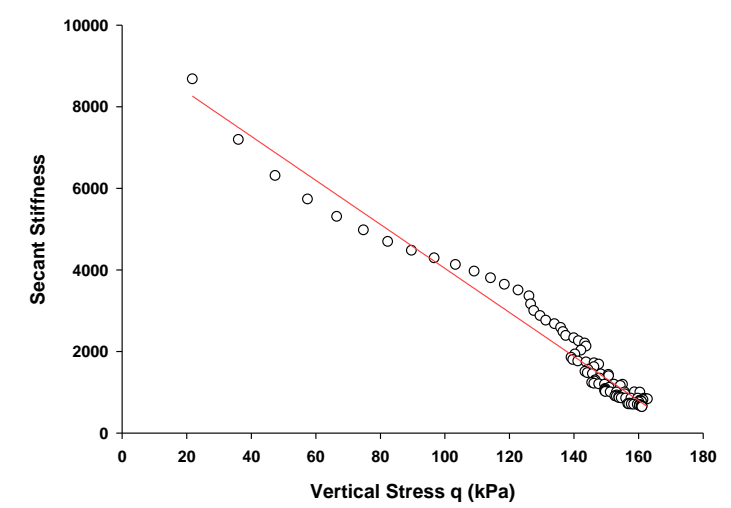

Figure 5. Presentation of the Decourt zero stiffness method for $\phi=28^{\circ}$ and $B=1 \mathrm{~m}$.

\subsection{Decourt Zero Stiffness Method}

Decourt [22] developed a method related with the relationship between secant stiffness $(\mathrm{Ks}=\mathrm{q} / \mathrm{s})$ and stress (q). In this method, stress and secant stiffness values are determined and a linear regression line should be applied. Stress that secant stiffness is equal to zero is defined as the bearing capacity of the foundation. There is a simple example of the Decourt [10] zero stiffness method for $\phi=28^{\circ}$ and $B=1 \mathrm{~m}$ as shown in Figure 5. In 
this example, the bearing capacity calculated with this method is found as $175.75 \mathrm{kPa}$ [10].

\section{Numerical Analysis}

As mentioned before, no depth factors are given in Eurocode. In order to make a comparison between the analytical methods, in this study, shallow strip footings rested on surface were used in the analysis $\left(D_{f}=0\right)$. Therefore, the second term of bearing capacity equations $(2.1,2.3,2.4,2.5)$ became zero. In addition, there are two procedures applied to obtain the bearing capacity of shallow foundations which are settlement control and graphical approaches for the numerical methods (Brinch-Hansen, De Beer, Chin, s/B, and Decourt zero stiffness). This makes it easy to compare analytical and numerical methods. The bearing capacity of the shallow strip foundation on a homogeneous isotropic sandy soil was calculated. A total of 56 analyzes were carried out by changing the foundation width (B) between $1 \mathrm{~m}$ and $3 \mathrm{~m}$ (except $1.25 \mathrm{~m}$ ) in 25 $\mathrm{cm}$ intervals for the soil having internal friction angles of 28, 30, 32, 34, 36, 38 and 40 degrees. The MohrCoulomb material model was chosen in order to make a comparison between analytical bearing capacity approaches. Soil parameters used in the analyzes are presented in Table 2.

Table 2. Parameters of soils used in analysis [10]

2. Parameters of soils used in analysis [10]

\begin{tabular}{llllll}
$\mathrm{kN} / \mathrm{m}^{2}$ & $\mathrm{kN} / \mathrm{m}^{3}$ & ${ }^{\circ}$ & ${ }^{\circ}$ & $\mathrm{kN} / \mathrm{m}^{2}$ & \\
\hline 0.5 & 18.6 & 28 & 0 & 12500 & 0.351
\end{tabular}

$\begin{array}{lllllll}0.5 & 19.0 & 30 & 0 & 17500 & 0.333\end{array}$

$\begin{array}{llllll}0.5 & 19.6 & 32 & 2 & 22500 & 0.320\end{array}$

$\begin{array}{llllll}0.5 & 20.1 & 34 & 4 & 27500 & 0.306\end{array}$

$\begin{array}{llllll}0.5 & 20.5 & 36 & 6 & 35000 & 0.291\end{array}$

$\begin{array}{llllll}0.5 & 20.8 & 38 & 8 & 45000 & 0.278\end{array}$

$\begin{array}{llllll}0.5 & 21.0 & 40 & 10 & 55000 & 0.263\end{array}$

$* \mathrm{E}=$ modulus of elasticity, $\mathrm{c}=$ cohesion, $\phi=$ angle of internal friction, $v=$ Poisson's

ratio, $\psi=$ angle of dilatation

Cohesion was used as $0.5 \mathrm{kPa}$ since selecting cohesion as " 0 " in order to abstain from some trouble with numerical modelling and material matrices. Unit weight and internal friction angles used in the analysis were selected in the recommended graph of Navfac (1986) [23] for well-graded sandy soil. The dilatation angle $(\psi)$ in the analysis is calculated as " $\phi$-30" as given in the Bolton (1986) [24] equation widely used in the literature. Poisson's ratio is calculated with Equation 2.6 given below:

$$
v=\frac{1-\sin \phi}{2-\sin \phi}
$$

The modulus of elasticity is ranged between 10-20 MPa for loose sand [25]. In order to find out the effect of elasticity modulus on the bearing capacity were determined with a simple analysis in the program. For this purpose, numerical models having $\mathrm{B}=1 \mathrm{~m}$ and $\phi=30^{\circ}$ were used. Elasticity modulus values were selected as 10000, 15000, 17500 and $20000 \mathrm{kPa}$.
As seen in Table 3, selecting $\mathrm{E}$ as 15000,17500 or $20000 \mathrm{kPa}$ has no significant effect (the difference is smaller than $3 \%$ ) on bearing capacity. Therefore, 17500 $\mathrm{kPa}$ was used in the analysis when $\phi=30^{\circ}$.

Table 3. The effect of elasticity modulus on the ultimate bearing capacity of $B=1 \mathrm{~m}$ and $\phi=30^{\circ}$.

\begin{tabular}{llllll}
\hline $\mathrm{E}$ & $\mathrm{BH}$ & $\mathrm{DB}$ & $\mathrm{DZS}$ & $\mathrm{SB}$ & $\mathrm{CH}$ \\
$\mathrm{kPa}$ & $\mathrm{kPa}$ & $\mathrm{kPa}$ & $\mathrm{kPa}$ & $\mathrm{kPa}$ & $\mathrm{kPa}$ \\
\hline 10000 & 184.74 & 178.09 & 249.32 & 179.57 & 242.91 \\
15000 & 192.68 & 177.22 & 237.57 & 196.02 & 225.38 \\
17500 & 190.15 & 180.61 & 234.85 & 194.39 & 223.56 \\
20000 & 193.64 & 177.24 & 233.74 & 191.20 & 226.88 \\
\hline${ }^{*} \mathrm{E}=$ modulus of elasticity, BH = Brinch Hansen, DB= De Beer, DZS=Decourt Zero
\end{tabular}

In granular soils, bearing capacity failure occurs at displacements around $5 \%$ and $15 \%$ of the foundation width [3]. In some cases, failure may occur at a $25 \%$ displacement of the foundation width. Therefore, displacement was selected as $25 \%$ of the foundation width in order to execute safer analysis. Analyses were done to determine the displacement velocity applied for the foundation. For this purpose, 0.002, 0.0025, 0.003, 0.0035 and $0.004 \mathrm{~m}$ displacement velocity values were selected for the analysis having a foundation width (B) of $1 \mathrm{~m}$ and internal friction angle $(\phi)$ of $28^{\circ}$. As seen in Figure 6 , the velocity of displacement has no significant effect on displacement-stress.

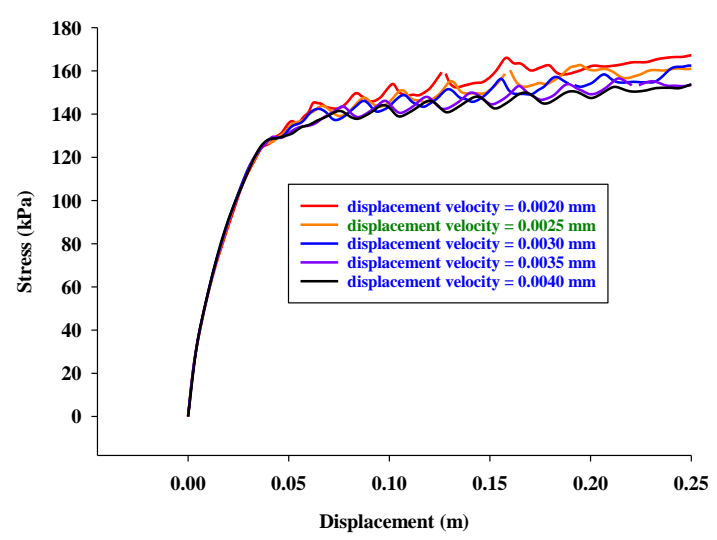

Figure 6. The effect of displacement velocity on the stress-displacement curve for $\mathrm{B}=1 \mathrm{~m}$ and $\phi=28^{\circ}$.

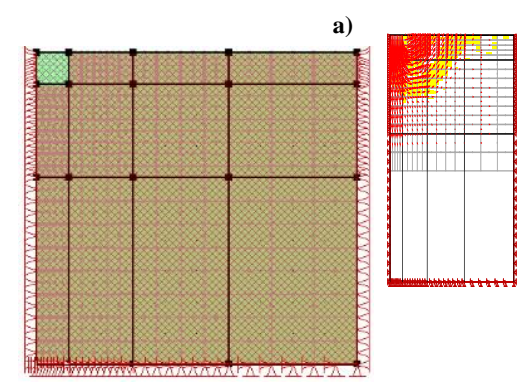

b)

Figure 7. a) Finite element mesh (b) deformation results after analysis. 
Figure $7 \mathrm{a}$ shows the application of the finite element mesh for the model and Figure $7 \mathrm{~b}$. shows the vector

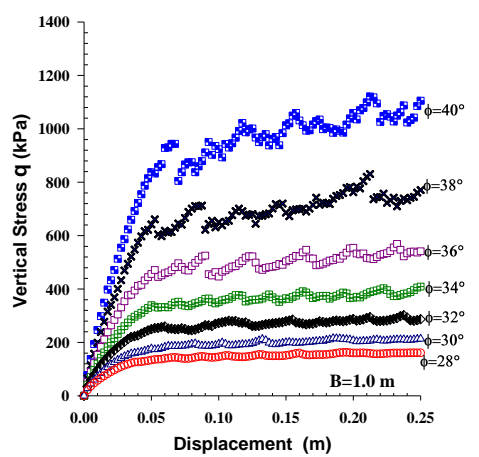

a)

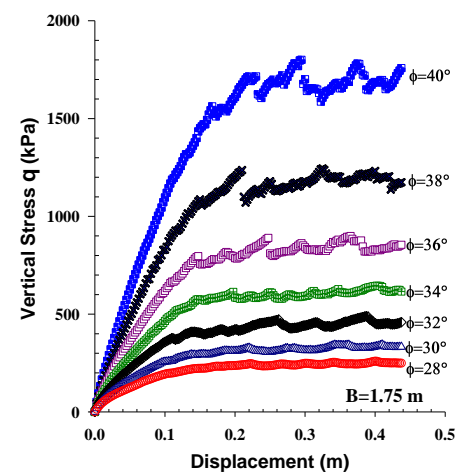

c)

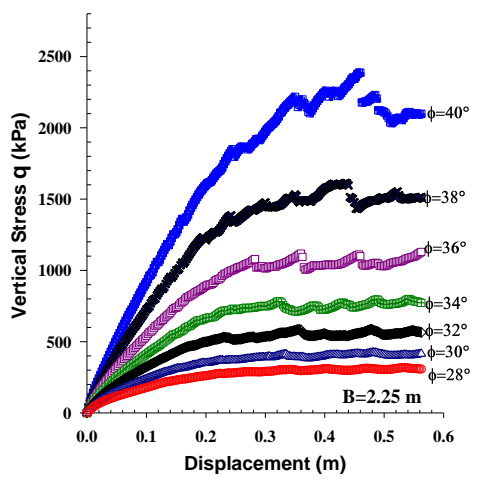

e)

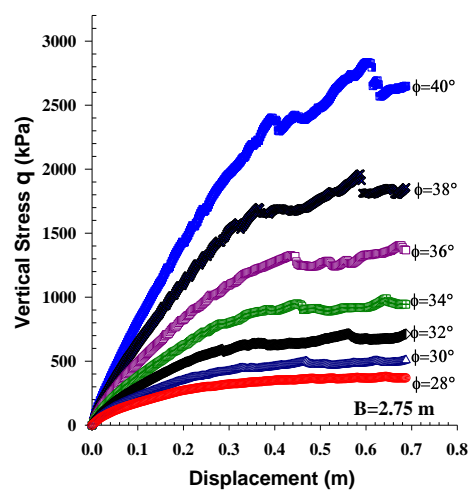

g) orientations of the deformations because of the analysis.

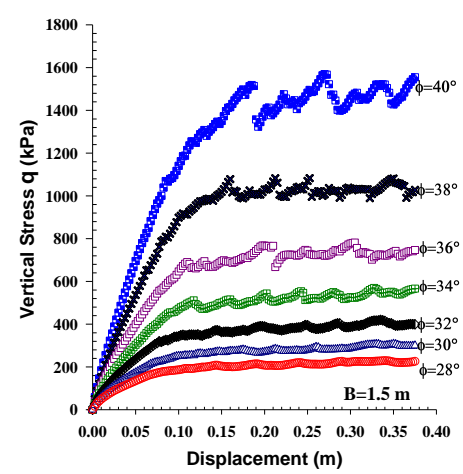

b)

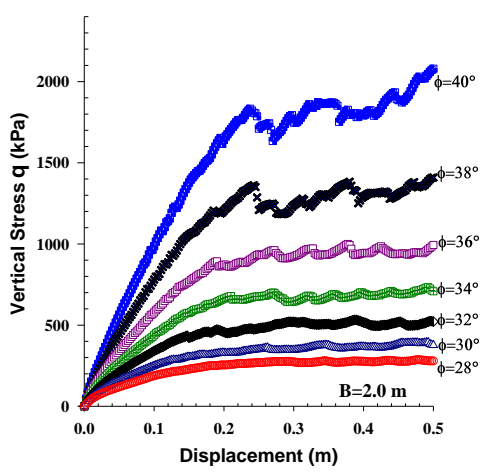

d)

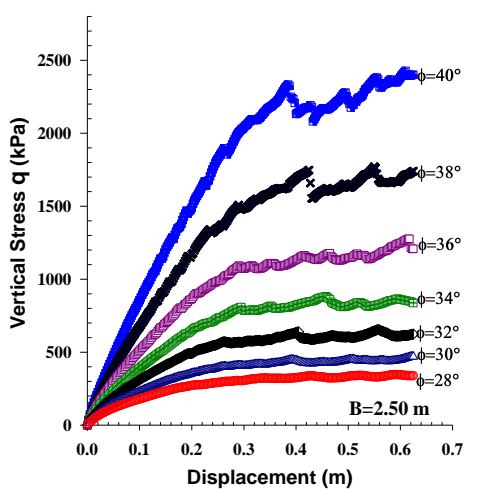

f)

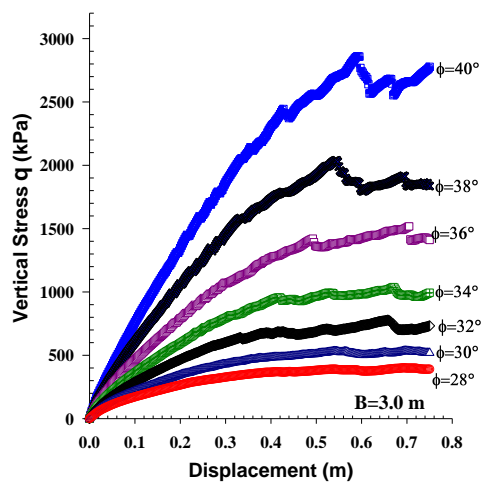

h)

Figure 8. Stress-deformation graph obtained after numerical analysis for different foundation widths a) $B=1 \mathrm{~m} \mathbf{b}$ ) $\mathrm{B}=1.5 \mathrm{~m}$ c) $\mathrm{B}=1.75 \mathrm{~m} \mathrm{~d}) \mathrm{B}=2 \mathrm{~m}$ e) $\mathrm{B}=2.25 \mathrm{~m} \mathrm{f)} \mathrm{B}=2.5 \mathrm{~m} \mathrm{g)} \mathrm{B}=2.75 \mathrm{~m} \mathrm{~h}) \mathrm{B}=3.0 \mathrm{~m}$ 
In the analyzes, unit deformation was given to the points corresponding to the foundation. Deformation values were increased step by step wisely and boundary forces corresponding to the points of the unit deformation were found. Loading ranges were selected between 0.0025 and $0.005 \mathrm{~mm}$ according to the base width [17]. In addition, the rough foundation system was modeled by keeping the points under the foundation in the $x$ direction.

In the analyzes, 8-noded isoparametric quadrilateral elements were used. For the finite element mesh, the same element but different element sizes are used for 12 regions in the model. In the regions close to the foundation, the finite element network is compacted and the element size is made smaller than the other regions. As distance increased from the foundation, the element size was increased

\section{Results and Discussions}

In this study, the bearing capacity of the strip foundations resting on sandy soils with different internal friction angles was determined by analytical and numerical methods. Figure 8 gives the results of numerical analysis. When the load-deformation graphs are examined for different foundation dimensions of the loose soil $\left(\phi=28^{\circ}\right)$ model, elastic and rigid plastic deformations can be easily distinguished from each other, especially in cases where the foundation width is small. However, when the foundation width increases, it becomes difficult to distinguish between the elastic region and the transition region of the plastic region. Therefore, it is necessary to find the ultimate load value using estimation methods. In dense soil $\left(\phi=40^{\circ}\right)$ models as seen in Figure 8, oscillations occur as the base width increases in the load-deformation graph in the plastic region. This oscillation phenomenon was also observed by other researchers $[6,7,9,10,13]$, especially in the Mohr-Coulomb model, and it was reported that the magnitude of oscillation was increased by the internal friction angle and the finite element mesh structure [9]. The finite element mesh must be optimized for each foundation width a)

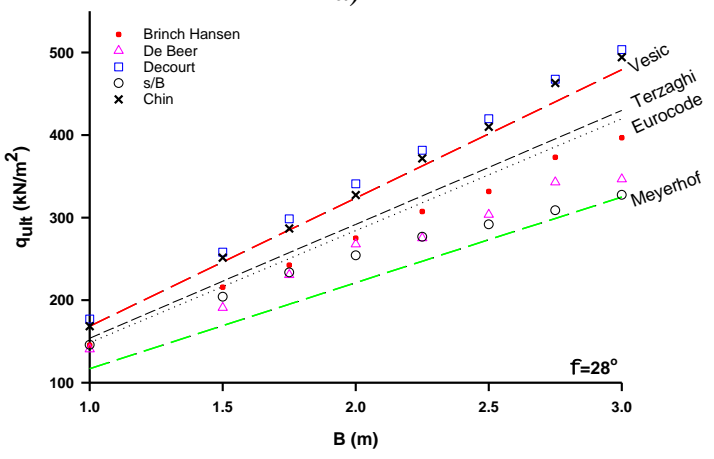

b)

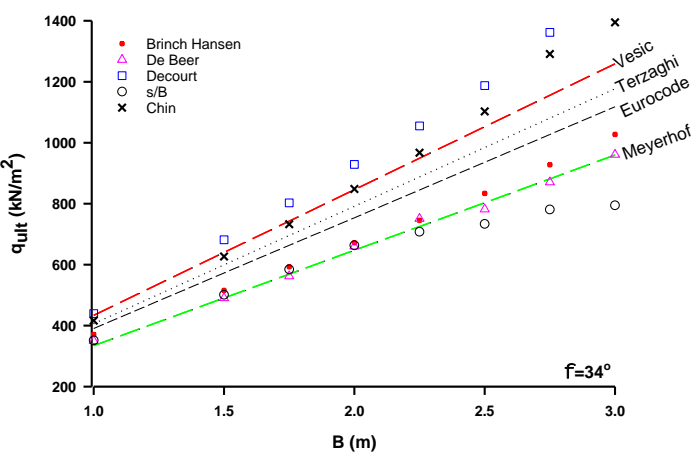

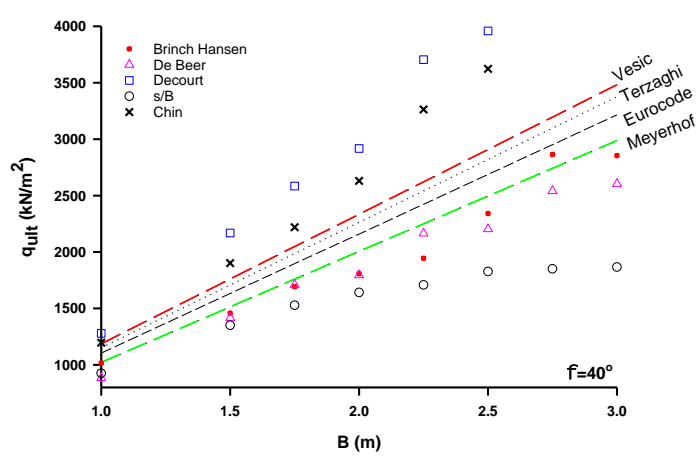

c)

Figure 9. Comparison of numerical and analytical methods with different foundation widths a) $\phi=28^{0}$

b) $\phi=34^{0}$ c) $\phi=40^{0}$

Figure 9 a shows the bearing capacity results obtained by both analytical and numerical methods for different foundation widths on a loose soil with an internal friction angle $\phi=28^{\circ}$. Among the analytical methods, the maximum bearing capacity values were obtained from
Vesic's [3] method. The Meyerhof bearing capacity values were lower than all bearing capacity methods. The biggest differences in bearing capacity values are between Vesic's [3] bearing capacity and the Meyerhof bearing capacity methods, with a difference of $44 \%$ for 
a foundation width of $1 \mathrm{~m}$ and $47 \%$ for a foundation width of $3 \mathrm{~m}$. The bearing capacity values obtained by numerical approaches fall between Vesic's [3] bearing capacity and the Meyerhof [2] bearing capacity in the loose soil model. The bearing capacity results obtained by the Chin [20] estimation method give the highest values compared to other methods. There is a $5 \%$ difference between the largest and smallest value for $\mathrm{B}=1 \mathrm{~m}$. Nevertheless, as the width of the foundation increases, the difference between them increases to 35 $\%$. Although the differences reach to $35 \%$, numerical methods except the Decourt [22] zero stiffness still fall in the region between Vesic [3] and Meyerhof methods which means that numerical methods and analytical methods are incompatible with each other for this example.

Figure $9 \mathrm{~b}$ gives the results of the analysis when $\phi=34^{\circ}$. In the analytical methods, the Meyerhof [2] bearing capacity value is the lowest one according to the other methods. The biggest differences in the analytical methods are obtained with the Vesic [3] and Meyerhof [2] methods. These differences are $29.84 \%$ for $1 \mathrm{~m}$ of foundation width and $31.15 \%$ for $3 \mathrm{~m}$ foundation width. In the numerical prediction methods, the Decourt [22] zero stiffness method gives the highest bearing capacity values. The lowest bearing capacity values calculated for $1,1.5,1.75$ and $2 \mathrm{~m}$ of foundation width were obtained from s/B method. For other foundation widths, the De Beer [19] method gives the lowest values. The biggest differences in the numerical method are $25.64 \%$ for $1 \mathrm{~m}$ of foundation width and $84 \%$ for $3 \mathrm{~m}$ foundation width. The lowest bearing capacity values are obtained from different methods while comparing numerical and analytical methods. The De Beer [19] method gives the lowest value for $\mathrm{B}=1.75 \mathrm{~m}$, the Meyerhof method gives the lowest values for $1,1.5$ and $2 \mathrm{~m}$. For other foundation widths, s/B method has the lowest value. The biggest differences in both analytical and numerical methods are $31.58 \%$ for $1 \mathrm{~m}$ of foundation width and $58.48 \%$ for $3 \mathrm{~m}$ foundation width. In Figure 9b, s/B and Chin [20] transformed axes methods started to move away from the colored region when $\mathrm{B}=2.25 \mathrm{~m}$ while the Decourt [22] zero stiffness method does not fall into the region after $B=1 \mathrm{~m}$. On the contrary, the De Beer [19] and Brinch Hansen [18] methods seem to be inside of the region for all foundation widths.

In Figure 9c, the results of the bearing capacity with numerical and analytical methods for strip foundations having different foundation width and $40^{\circ}$ of internal friction angle are shown. Similar results are given in Figure 9a and Figure 9b, Vesic [3] gives the highest and Meyerhof [2] gives the lowest bearing capacity value. The Eurocode [4] bearing capacity is $4.84 \%$ larger than Terzaghi [1] for $2 \mathrm{~m}$ of B and 5.03\% larger for $3 \mathrm{~m}$ of B. The biggest differences in bearing capacity values calculated with analytical methods are obtained as
$16.16 \%$ for $B=1 \mathrm{~m}$ and $16.57 \%$ for $\mathrm{B}=3 \mathrm{~m}$. In the numerical method, the biggest differences for $\mathrm{B}=1 \mathrm{~m}$ is $44.63 \%$ while it is $172.26 \%$ for $B=3 \mathrm{~m}$. The biggest bearing capacity values were obtained from the Decourt [22] zero stiffness method for all foundation widths. The method of $\mathrm{s} / \mathrm{B}$ gave the lowest $\mathrm{q}_{\mathrm{u}}$ (bearing capacity) values for all foundation widths except $B=1 \mathrm{~m}$. The De Beer method gives the lowest qu (bearing capacity) for $1 \mathrm{~m}$. When comparing analytical and numerical methods together, the biggest differences among numerical and analytical methods are $34.23 \%$ for $\mathrm{B}=1 \mathrm{~m}$ and $86.79 \%$ for $\mathrm{B}=3 \mathrm{~m}$. Differences between numerical methods in the strict soil model are quite large and do not fall between the results of analytical methods. In particular, the Chin [20] estimation method gives much larger values than other analytical method results. Another observed result in Figure 7 is that the s/B approach gives lower values compared to other methods with an increasing base width. As seen in Figure 8, in both types of soil models, as the foundation width increases, the transition region from the elastic region to the plastic region is in a wider range. Therefore, the $\mathrm{s} / \mathrm{B}$ method offers smaller values as a result in large foundation systems. The main reason for this is assumed to be the oscillations in the load-deformation graphs as the base width increases.

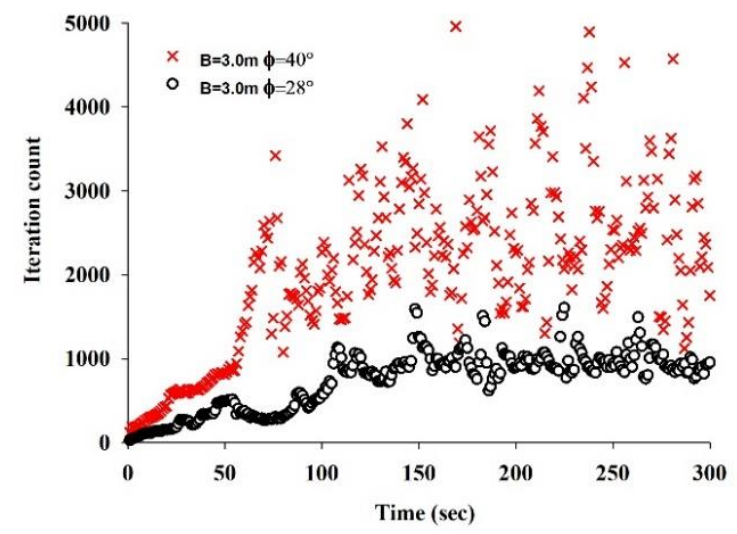

Figure 10. Iteration count-time relationship for a) $\phi=28^{\circ} \mathrm{B}=1 \mathrm{~m}$ b) $\phi=40^{\circ} \mathrm{B}=3 \mathrm{~m}$

In Figure 10, iteration count-time relations obtained after analysis are shown. Figure 10a is an example of loose sand having $\phi=28^{\circ}$ and Figure $10 \mathrm{~b}$ is an example of dense sand $\left(\phi=40^{\circ}\right)$. In Figure 10a, approximately 1300-1400 iteration is enough to determine the stress values while 7000 iteration is needed to evaluate the stress value at some mesh elements. The main reason of oscillations that were seen in Figure 8 when $\phi=40^{\circ}$ can be clearly understood in Figure 10 . When the soil is getting denser, it becomes harder to evaluate the failure stress.

Figure 11 gives the results of both numerical and analytical analysis. The average analytical (theoretical) 
bearing capacity values have been used for comparison of the analytical and numerical methods.

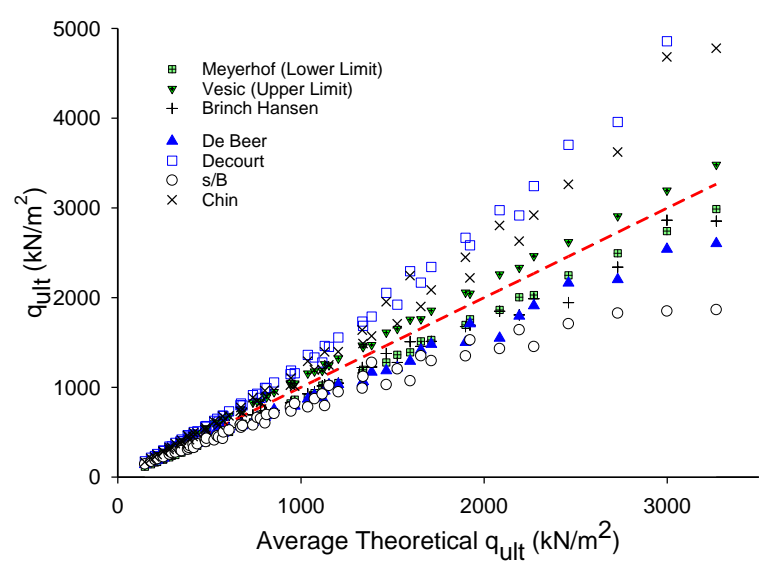

Figure 11. Summary of all analyses.

$\mathrm{X}$ axis indicates the average bearing capacity of all analytical methods for different foundation widths while $\mathrm{y}$ axis shows the bearing capacity of whole methods alone. The red dashed-line indicates the average bearing capacity values. As known, it is not possible to break the system completely in a finite element method However, it can converge to the fracture value, so it is expected to be slightly smaller than the results of analytical methods.

\section{Conclusion}

It is clearly seen that the bearing capacity values obtained from analytical and numerical methods begin to diverge from each other as $\phi$ and B increases. The De Beer method seems to be closer to the results of the analytical methods compared to other numerical methods. Method of $\mathrm{s} / \mathrm{B}$ is coherent up to average theoretical bearing capacity ( $\mathrm{q}_{\text {ult }}$ ) value reaches 2000 $\mathrm{kPa}$ as seen in Figure 11. after average qult is higher than $2000 \mathrm{kPa}$, this method seems to be not suited since the qult value is almost unchanged. Decourt [17] stiffness and Chin [20] transformed axes methods are the worst ones compared to the others.

In conclusion, numerical methods give more coherent results for loose sandy soils compared to dense soils. These results are apparently due to two reasons. First, although the Mohr-Coulomb Failure Criterion is mostly used for granular soils, it has some limitations to express stress-strain finite element modelling. As seen in Figure 10, when the soil is getting denser, it becomes harder to numerically evaluate the failure stress. Second, the displacement values corresponding to the bearing capacity calculated by each of the numerical methods (De-Beer, Chin, s/B, Decourt) is different.

In addition, this study showed that when calculating the bearing capacity of a shallow foundation, the soil parameters obtained in the field and in the laboratory and the foundation dimensions to be constructed should be carefully calculated for each project. Since the calculation methods give different bearing capacity values, these bearing capacity calculations should be obtained in several to check for the safety of the foundation.

\section{Acknowledgement}

Geostudio 2012 software used in the study was supported by Zonguldak Bulent Ecevit University for an infrastructure project. 2012-17-11-03.

\section{Author's Contributions}

Emrah Dağlı: Performed all analytical and numerical analyses of the research, drafted and wrote the manuscript.

Ömer Faruk Çapar: Conceived and designed the analyses, helped in result interpretation and manuscript writing.

All authors discussed the results and contributed to the final manuscript.

\section{Ethics}

There are no ethical issues after the publication of this manuscript.

\section{References}

1. Terzaghi, K. Theoretical Soil Mechanics; Harvard Univ. Press: John Wiley \& Sons, America, 1943; pp 510.

2. Meyerhof, G. 1943. The ultimate bearing capacity of foundations. Geotechnique; 2: 331-332.

3. Vesic, A. 1973. Analysis of ultimate loads of shallow foundations Journal of the Soil Mechanics and Foundations Division; 99 (SM-1): 45-73.

4. Bond, A. and Harris, A. Decoding Eurocode; Press: Taylor \& Francis, America, 2008; pp 616

5. Sieffert, J.G., Bay-Gress, C. 2000. Comparison of the European bearing capacity calculation methods for shallow foundations Geotechnical Engineering, Institution of Civil Engineers 143 6574.

6. Manoharan, N., and Dasgupta, S.P. 1995. Bearing Capacity of Surface Footings by Finite Elements. Computers and Structures; 54 (4): 563-586.

7. Elhakim, A. Evaluation of Shallow Foundation Displacements Using Soil Small-Strain Stiffness; Georgia Institute of Technology, Civil and Environmental Engineering, Doctor of Philosophy, America, 2005; pp 396.

8. Loukidis, D., Chakraborty, R., and Salgado, R. 2008. Bearing capacity of strip footings on purely fractional soil under eccentric and inclined loads. Canadian Geotechnical Journal; 45 (6): 768 787.

9. Loukidis, D., and Salgado, R. 2009. Bearing capacity of strip and circular footings in sand using finite elements. Computers and Geotechnics; 36: 871-879.

10. Dağl1, E. Calculation of Bearing Capacity of Cohesionless Soils By Numerical and Analytical Methods; Zonguldak Bulent Ecevit 
Univ. Institute of Science, Master's Thesis in Turkish, Turkey, 2013; pp 130.

11. Ghazavai, M., and Eghbali, A.H. 2013. New geometric average method for calculation of ultimate bearing capacity of shallow foundations on stratified sands. ASCE International Journal of Geomechanics; 13 (2): 101-108.

12. Nguyen, D.L., Ohtsuka S., and Kaneka, K. 2016.. Ultimate Bearing Capacity of Footing on Sandy Soil Against Combined Load of Vertical, Horizontal and Moment Loads. Int. J of Geomate; 10 (1): 1649-1655.

13. Yahia-Cherif, H., Mabrouki A., Benmeddour D., and Mellas, M 2017. Bearing Capacity of Embedded Strip Footings on Cohesionless Soil Under Vertical and Horizontal Loads. Geotech Geol Eng; 35: 547-558.

14. Sakleshpur, V.A., and Reddy, C.N.V.S. 2017. A Comparative Study on Bearing Capacity of Shallow Foundations in Sand from $\mathrm{N}$ and $\phi$. J. Inst. Eng. India Ser. A; 98 (4): 355-365.

15. Bowles, J. Foundation Analysis and Design; Harvard Univ. Press: McGraw-Hill, America, 1995; pp 1230.

16. Geostudio, Stress-Deformation Modelling with Sigma/W 2012 Geo-Slope International Ltd; Canada, 2012; pp 221.

17. Potts, D.M. and Zdravkovic, L. Finite Element Analysis in Geotechnical Engineering Volume 2: Application; Press: Thomas Thelford Publishing, England, 2001; pp 427.

18. Hansen, B. 1963. A general formula for bearing capacity. Danish, Geotechnical Institute, Bulletin; 11: 38-46.

19. De Beer, E. 1970. Experimental determination on the shape factors and the bearing capacity factors of sand. Geotechnique; 20 (4): $387-411$.

20. Chin, F. 1971. Discussion to pile tests: Arkansas river project. ASCE Journal of Soil Mechanics and Foundation; 97 (6): 930932.

21. Amar, S., Baguelin, F., Canepa, Y., and Frank, R. 1994. Experimental study of the settlement of shallow foundations. Vertical and Horizontal Deformation of Foundations and Embankments; 2 (40): 1602-1610.

22. Decourt L 1999. Behaviour of Foundations under Working Load Conditions, Proceedings of The XI Panamerican Conference On Soil Mechanics And Geotechnical Engineering; Foz Du Iguassu, Brazil, 4: 453-487.

23. Navfac DM-7.02. Foundations \& Earth Structures Design Manual 7.02, Washington, 1986; pp 279.

24. Bolton, M. D. 1986. The strength and dilatancy of sands, Geotechnique; 36 (1): 65-78.

25. Budhu, M. Foundations and earth retaining structures, John Wiley \& Sons, Arizona, 2007; pp 483. 